\title{
Novel Optogenetic Approaches in Epilepsy Research
}

\author{
Elvis Cela ${ }^{1,2}$ and Per Jesper Sjöström ${ }^{1 *}$
}

${ }^{1}$ Brain Repair and Integrative Neuroscience Program, Centre for Research in Neuroscience, Department of Medicine, Department of Neurology and Neurosurgery, The Research Institute of the McGill University Health Centre, Montreal General Hospital, Montreal, QC, Canada, ${ }^{2}$ Integrated Program in Neuroscience, McGill University, Montreal, QC, Canada

\section{OPEN ACCESS}

Edited by: Keith Mathieson, University of Strathclyde, United Kingdom

Reviewed by: Igor Timofeev, Laval University, Canada Vassiliy Tsytsarev, University of Maryland, College Park,

United States

*Correspondence:

Per Jesper Sjöström jesper.sjostrom@mcgill.ca

Specialty section: This article was submitted to

Neural Technology, a section of the journal

Frontiers in Neuroscience

Received: 31 May 2019

Accepted: 22 August 2019

Published: 06 September 2019

Citation:

Cela E and Sjöström PJ (2019) Novel Optogenetic Approaches

in Epilepsy Research.

Front. Neurosci. 13:947.

doi: 10.3389/fnins.2019.00947
Epilepsy is a major neurological disorder characterized by repeated seizures afflicting $1 \%$ of the global population. The emergence of seizures is associated with several comorbidities and severely decreases the quality of life of patients. Unfortunately, around $30 \%$ of patients do not respond to first-line treatment using anti-seizure drugs (ASDs). Furthermore, it is still unclear how seizures arise in the healthy brain. Therefore, it is critical to have well developed models where a causal understanding of epilepsy can be investigated. While the development of seizures has been studied in several animal models, using chemical or electrical induction, deciphering the results of such studies has been difficult due to the uncertainty of the cell population being targeted as well as potential confounds such as brain damage from the procedure itself. Here we describe novel approaches using combinations of optical and genetic methods for studying epileptogenesis. These approaches can circumvent some shortcomings associated with the classical animal models and may thus increase the likelihood of developing new treatment options.

Keywords: epilepsy, optogenetics, seizures, animal models, plasticity, kindling

\section{INTRODUCTION}

Epilepsy is a common neurological disorder affecting about $1 \%$ of the global population (Engel and Pedley, 2008; Brodie et al., 2009). It is defined as a chronic condition associated with at least one seizure and associated neurological, psychological, as well as cognitive consequences (Fisher et al., 2014). A seizure is defined as a transient occurrence of symptoms such as aberrant speech, perception, or attention thought to result from aberrant neuronal activity in the brain (Fisher et al., 2005).

Seizures may originate in different brain areas and have varying symptoms associated with the area of initiation (Brodie et al., 2009; Kwan et al., 2011). Once seizures arise, they are more likely to reoccur, giving rise to the notion that "seizures beget seizures" (Ben-Ari et al., 2008). There are, however, different types of seizures. Broadly, convulsive seizures are associated with body movements while non-convulsive seizures such as absence seizures are not. Epilepsy can also be crudely categorized into generalized or focal epilepsies, even though epilepsies that start as focal may eventually generalize (Engel, 2005).

Seizure types can also be divided into those that arise from genetic predispositions and those that are acquired. Genetic predispositions for developing seizures can for example arise as a result of channelopathies, which are each associated with specific seizure types and probabilities of having certain symptoms (Chang and Lowenstein, 2003; Glasscock et al., 2007). Other examples 
include mutations in transcriptional regulators such as JAKSTAT (Grabenstatter et al., 2014), proteins involved in cell growth such as mTOR (Way et al., 2012), or expansions in noncoding regions (Ishiura et al., 2018). On the other hand, acquired epilepsy can arise for many different reasons including: traumatic brain injury, infection, cancer, cerebrovascular disorder, autoimmune disorder, and developmental malformation (Berkovic et al., 2006).

Although traumatic brain injury accounts for $5 \%$ of epilepsies, typically a considerable period of time has to pass before the first seizures emerge (Herman, 2002). This latent period of epileptogenesis is thought to be due structural reorganization and network rewiring, although the details are poorly understood. For this reason, epileptogenesis is a central focus of animal studies in efforts to improve treatment outcomes (Chauvette et al., 2015).

Once epilepsy has been diagnosed, there are several options for treatment with two common avenues being surgical resection of diseased tissue and treatment with ASDs (Kwan et al., 2011). ASD treatment is typically prescribed but unfortunately approximately $30 \%$ of patients do not respond to this type of treatment (Kwan et al., 2011). Furthermore, patients taking ASDs may suffer from a plethora of side effects, such as drowsiness, dizziness, blurred vision and tremor (Perucca and Gilliam, 2012). Factors that contribute to a poor prognosis include presence of multiple seizure types, presence of generalized tonic-clonic seizures, and high seizure frequency before treatment (Kwan and Brodie, 2000; Kwan et al., 2011). Limitations of ASDs in managing seizures may arise from problems that plague many drugs, such as failure of optimal dosage and reliance on serum drug concentrations in lieu of monitoring clinical symptoms (Kwan et al., 2011). The lack of treatment specificity, along with the high percentage of ASD non-responders who as a consequence suffer a lower quality of life, necessitates a more advanced understanding of the basic mechanisms of epileptogenesis. Importantly, treating seizures with ASDs does not generally undo the process of epileptogenesis, as evidenced by the seizure remittance and relapse rates (Shorvon and Goodridge, 2013). This is not surprising, since epileptogenesis presumably involves structural and morphological changes that are unlikely to be reversed by ASDs. ASDs work best in suppressing generation, propagation and severity of seizures themselves (Chen Z. et al., 2018). Essentially, we need to better elucidate how seizures initially arise in the healthy brain and establishing better animal models is the key to this.

\section{CLASSICAL ANIMAL MODELS OF EPILEPSY}

A major thrust of epilepsy research has been to recapitulate seizures and their associated symptoms in animal models and study their progression over time. As a result, a variety of animal models have been developed to study different aspects of epilepsy. Two enduring groups of models used to study chronic epilepsy are genetic and acquired, further subdivided into electrical or chemical induction (Löscher, 2002). Genetic animal models can involve animals with spontaneous or induced mutations resulting in recurrent seizures. For example, mutations in GluA4 AMPARs have been causally linked to absence seizures (Paz et al., 2011). On the other hand, acquired electrical models, such as kindling, rely on gradual development of evoked seizures after repeated stimulation in initially healthy animals (Löscher, 2011). In chemical induction models, proconvulsants such as pentylenetrazol, kainic acid, or pilocarpine are injected into an animal to induce chronic seizures (Löscher, 2002). These chemicals act on receptors critically involved in synaptic transmission, thereby disturbing the excitatory-inhibitory balance and resulting in seizures (Fisher, 1989). On the other hand, 4-aminopyridine (4-AP) another commonly used proconvulsant - acts mainly upon voltage-activated potassium channels, where it promotes elevated action potential firing due to faster recovery after inactivation (Storm, 1988), while kainic acid acts upon glutamate receptors (Olney et al., 1974). Several widely used convulsants act by antagonism of the GABA receptors (GABARs), thereby promoting excitability in the brain (Fisher, 1989). However, chemical kindling may also be elicited by agents such as cholinesterase agonists, opiates, local anesthetics, neurotoxicants, as well as excitatory amino acids (Stripling and Ellinwood, 1977; Cain, 1983; Mori and Wada, 1989; Gilbert, 1992).

Administration of chemical convulsants can be intracerebral or systemic. Chemical convulsants can be combined with electrical stimulation, or can be delivered alone repeatedly in a kindling paradigm (Cain, 1981). Finally, chemicals administered alone can cause status epilepticus if administered at high enough doses. For example, Clark et al. (1992) found that a single highdose injection of cocaine $(65 \mathrm{mg} / \mathrm{kg})$ instantly caused seizures, whereas a lower dose $(40 \mathrm{mg} / \mathrm{kg})$ required multiple injections over several days to eventually elicit seizures.

What advantages does chemical kindling present over other animal model of epilepsy? First, chemoconvulsants such as kainic acid preferentially target the hippocampus, even when administered systemically, mimicking temporal lobe epilepsy (TLE) in humans (Nadler et al., 1978). Secondly, chemical kindling results in structural changes that resemble those in partial seizures, as seen with pilocarpine injections (Cavalheiro et al., 1991). Thirdly, chemoconvulsants such as PTZ or strychnine can be used as acute seizure models to screen ASD action without necessarily resulting in chronic epilepsy (Löscher, 2011).

There are also several drawbacks to using chemoconvulsants to study epilepsy. A main disadvantage is the lack of control over timing from chemoconvulsant injection to first seizure. Furthermore, variability in drug metabolism and dissemination from injection site adds uncertainty to the timing of the response and this is hard to control for. Finally, systemic injection of drugs can have off-target effects with unintended consequences secondary to seizure initiation. For example, kainic acid, which acts upon kainate receptors, has been used to model TLE seizures but the receptor distribution is not limited to the limbic structures (Li et al., 2001).

In electrical kindling models, healthy animals receive repeated electrical brain stimulation with what is an initially subconvulsive stimulus until it eventually elicits convulsions (Goddard et al., 
1969). Seizures are thus not necessarily spontaneous, but are typically evoked by the kindling stimulus, although spontaneous seizures may also develop eventually (Pinel and Rovner, 1978; Michael et al., 1998). Repeated induction of evoked focal seizures through kindling is highly reliable. In addition, seizures are initially expressed at the stimulated site and generalize to other parts of the brain with repeated stimulation (Wada and Sato, 1974).

During the discovery of electrical kindling it was found that stimulation efficacy depends on the brain area stimulated, with the amygdala requiring the fewest number of stimulations (Goddard, 1967). The brain region-specific differences in response to kindling are thought to arise in part from differential reactivity in stimulation sites themselves as well as the areas that they connect to (Sato et al., 1990). The amygdala, for example, has strong connections with motor areas and is able to generate interictal spikes early during kindling, indicating that epileptogenesis may be taking place (Hopkins and Holstege, 1978; Racine et al., 1988). Kindling efficacy can be further enhanced by bilateral instead of unilateral stimulation (Kogure et al., 2000).

The early behavioral responses of freezing in response to stimulation typically progresses to generalized seizures with bilateral clonus (Racine, 1972). Correspondingly, the initial brief epileptiform activity that follows stimulation becomes altered, resulting in increased duration, amplitude, and frequency of seizures, typically also with a decreased seizure threshold (Racine, 1972). Also, kindled animals retain a reduced threshold for seizures over months, which was initially thought of as analogous to long-term memory (Goddard, 1967). Thus, kindling recapitulates in an animal model several key processes such as the evolution from partial to generalized seizures as well as structural and morphological changes that occur in human epilepsies (Racine, 1972; Sutula, 2004).

Because of the close links between kindling and information storage in the brain via synaptic learning (Sjöström et al., 2008), kindling opens up possible avenues for studying runaway plasticity as a key causative agent in epileptogenesis (Goddard, 1967). For example, kindling has similar induction requirements as LTP, it can be promoted by prior LTP as well as reversed by plasticity paradigms similar to LTD (Cain, 1989; McEachern and Shaw, 1999). Kindling is furthermore dependent on NMDA receptors, and epilepsy is known for hundreds of years to be treatable with marijuana (Piomelli, 2003; Alger, 2004; Sjöström et al., 2008). Further work has shown that CB1Rs may modulate NR2B-containing NMDAR internalization (Di Maio et al., 2019) and that they can interact with NMDARs to protect cells from excitotoxic insults (Liu et al., 2009; Sanchez-Blazquez et al., 2013). In keeping with a link to plasticity, both NMDA and cannabinoid receptor signaling are key to spike-timing dependent plasticity and to regulation of neurotransmitter release in neocortex (Sjöström et al., 2003; Abrahamsson et al., 2017).

However, NMDARs are not the only receptors tying kindling to plasticity; AMPARs have been investigated for both contributions to seizures as well as potential therapeutic targets (Rogawski, 2011; Rajasekaran et al., 2012). For example, seizures in early life alter calcium-permeable AMPAR expression, suggesting that they may promote aberrant long-term plasticity during kindling in synapse-type-specific manner (Rakhade et al.,
2008; Larsen and Sjöström, 2015; Lalanne et al., 2016). There may also be a link between kindling-induced seizures and increased excitability of dendrites, which has been implicated in controlling plasticity (Bernard et al., 2004; Shah et al., 2004; Sjöström and Häusser, 2006; Sjöström et al., 2008).

What advantages does electrical kindling present over other animal models of epilepsy? First, electrical kindling allows precise focal activation of specific brain sites through anatomical targeting with the stimulating electrode. Second, it allows for reliable development of chronic seizures, as well as readily manipulated ictal and postictal periods. Lastly, behavioral alterations during stimulations start focally and evolve into generalized seizures, mimicking partial to complex seizure evolution in humans (Sato et al., 1990).

However, there are also several limitations to electrical kindling models. For example, using electrical kindling to study chronic epilepsy can be labor and time-intensive. Kindling typically also fails to capture a critical feature of epilepsy recurrent spontaneous seizures - unless the animal is "overkindled" through a large number of sessions (Pinel and Rovner, 1978; Michael et al., 1998). Since recurrent spontaneous seizures are a defining feature of epilepsy, this means kindling is not always identical to epilepsy, even though it may be useful as a model of key aspects of epilepsy, such as seizures. Finally, kindling is associated with injury and inflammation, which has been linked to higher seizure rates, making the contribution of pathological activity hard to distinguish from that of injury (Cavazos et al., 1994; Pitkänen et al., 2009).

To sum up, both electrical and chemical induction models reproduce many of the steps in seizure progression and related pathology underlying human epilepsies. However, because the perturbed cell population is unclear and because of the tissue trauma associated with the induction procedure, new approaches to study seizures are needed, e.g. using cell-specific targeting and activity manipulation. As we shall see below, optogenetics provides an indispensable tool here.

\section{NOVEL GENETIC AND OPTICAL APPROACHES TO EPILEPSY}

\section{Methods for Light-Driven Perturbation of Neuronal Activity}

The cellular basis of seizure formation continues to evade researchers, in part owing to the unknown cell populations that electrical kindling recruits. Experiments combining brain imaging methods, such as fMRI, with epilepsy animal models may be able to resolve brain areas participating in seizures but cannot resolve specific cell populations (Lenkov et al., 2013; Gottschalk et al., 2016). Therefore, a causal understanding of epileptogenesis necessitates genetic identification and manipulation of activity in specific target neurons. Optogenetics can circumvent these drawbacks by allowing genetic tagging and manipulation of activity in specified neuronal populations (Zemelman et al., 2002). This technique allows light-driven activation or inactivation of neurons, by the expression of light-gated ion channels such as Channelrhodopsin-2 (ChR2) or 
pumps such as Halorhodopsin (NpHR), respectively (Nagel et al., 2002; Boyden et al., 2005; Lima and Miesenböck, 2005; Chow et al., 2010; Yizhar et al., 2011). The rhodopsin later termed ChR2 was discovered in the algae Chlamydomonas reinhardtii, where it generates photocurrents contributing to phototaxis (Harz and Hegemann, 1991). Aside from NpHR, another widely used inhibitory opsin is Archaerhodopsin (Arch) which inhibits neuronal activity through influx of $\mathrm{H}^{+}$compared to NpHR's extrusion of $\mathrm{Cl}^{-}$ions (Nagel et al., 2002; Zhang et al., 2007; Chow et al., 2010).

Along with the first developed opsins used to activate and inhibit neurons, other variants include but are not limited to: G-protein-coupled receptors (opto-XRs) (Airan et al., 2009), vSWO/vLWO (Masseck et al., 2014), chloride channels (iC1C2, SwiChR) (Berndt et al., 2014) and chloride channel variants (JAWS) (Chuong et al., 2014), as well as sodium pumps (Inoue et al., 2013). Another approach has been to create a lightgated version of the ionotropic glutamate receptor (iGluR), which shares the advantage of millisecond manipulation of neuronal activity with optogenetics (Volgraf et al., 2006). Finally, reactive oxygen species can be used to inhibit neurotransmission after coupling to a light absorption by light-oxygen voltage domain (Shu et al., 2011). In summary, light-activated proteins open up novel approaches to studying epilepsy by permitting control of genetically defined neuronal populations, typically with millisecond precision.

\section{Genetic Targeting of Opsins}

One key advantage of optogenetics is modulation of activity in specific neurons, but how can opsins be targeted to different neuronal populations? First, opsins can be delivered using adeno-associated virus (AAV) or lentivirus containing a promoter targeting the cells of interest (Ponnazhagan et al., 1997; Dittgen et al., 2004). Furthermore, the serotype of the AAV itself can confer a degree of selectivity though specific tropism (Burger et al., 2004). Secondly, opsins can be expressed in transgenic animals using a combination of the Cre/loxP (Sauer, 1987) and/or Flp/Frt systems (Buchholz et al., 1998), which can add even more specificity through selective promoters (Fitzsimons et al., 2002). Finally, specific cell populations can be targeted using monosynaptic and/or transsynaptic tracing techniques. Retrograde tracing can be done using rabies virus (Rancz et al., 2011; Chatterjee et al., 2018) or wheat germ agglutinin (Libbrecht et al., 2017) in combination with Cre-dependent ChR2 expression (Gradinaru et al., 2010). Anterograde tracing can be done using Herpes simplex virus (Lo and Anderson, 2011) or certain AAV serotypes (Zingg et al., 2017). These techniques can also be combined to improve spatial and/or temporal selectivity, by employing intersectional targeting strategies. For example, Cre or Flp can be fused to an estrogen receptor (ER) ligand-binding domain (LBD) that is only sensitive to synthetic 4-hydroxytamoxifen (4-OHT). Upon 4-OHT administration, the ER-LBD translocated to the nucleus where it can mediate recombination (Dymecki and Kim, 2007; Sjulson et al., 2016). Thus, recombination can be temporally regulated by $4-\mathrm{OHT}$ injection.

\section{Putting a Brake on Seizures With Optogenetics}

Optogenetics has found multiple uses in neuroscience, including studying epilepsy where it has been used to both halt and initiate seizures (Table 1; Figure 1; Paz et al., 2013; Cela et al., 2019). The majority of studies attempting to optogenetically abate seizures have used classical animal models to induce epilepsy (Wykes et al., 2012; Wang et al., 2017).

Interneurons (INs) play a central role in many types of epilepsy and different populations of INs have been critically

TABLE 1 | Optogenetic epilepsy studies.

\begin{tabular}{|c|c|c|c|c|}
\hline References & Brake & Drive & Kindle & Area \\
\hline Cela et al., 2019 & & & $\checkmark$ & Motor \\
\hline $\begin{array}{l}\text { Khoshkhoo et al., } \\
2017\end{array}$ & & $\checkmark$ & & Motor \\
\hline Wykes et al., 2012 & $\checkmark$ & & & Motor \\
\hline $\begin{array}{l}\text { Assaf and Schiller, } \\
2016\end{array}$ & $\checkmark$ & $\checkmark$ & & Somatosensory \\
\hline Chang et al., 2018 & & $\checkmark$ & & Somatosensory \\
\hline
\end{tabular}

Berglind et al. $\quad \checkmark \quad$ CA3

2014

2018

Bui et al., 2018

Chen S. et al., 2018

Chiang et al., 2014

Krook-Magnuson

et al., 2013

Krook-Magnuson

et al., 2015

Ladas et al., 2015

Lu et al., 2016

Osawa et al., 2013

Sessolo et al., 2015

Shiri et al., 2015

Tonnesen et al.,

2009

Wang et al., 2017

Weitz et al., 2015

Yekhlef et al., 2015

$\checkmark$

Hippocampus

$\begin{array}{ll}\text { Entorhinal } & \text { cortex }\end{array}$

\begin{tabular}{lclll}
\hline $\begin{array}{l}\text { Krook-Magnuson } \\
\text { et al., 2014 }\end{array}$ & $\checkmark$ & & Lateral & Cerebellum \\
Kros et al., 2015 & $\checkmark$ & & LCN and MCN & \\
\hline Soper et al., 2016 & $\checkmark$ & & $\begin{array}{l}\text { Superior } \\
\text { colliculus }\end{array}$ & Midbrain \\
\hline Paz et al., 2013 & & $\checkmark$ & Ventrobasal & Thalamus \\
Sorokin et al., 2017 & $\checkmark$ & $\checkmark$ & Ventrobasal & \\
\hline
\end{tabular}

Studies to date using optogenetics either to interrupt ("Brake"), promote seizures ("Drive") or kindle ("Kindle") (also see Figure 1). DG denotes the Dentate gyrus, CA1 Cornu Ammonis subfield 1, CA3 Cornu Ammonis subfield 3, LCN lateral cerebellar nuclei, and MCN medial cerebellar nuclei. 
Acute

A

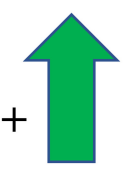

B

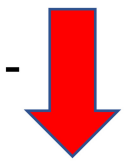

Chronic

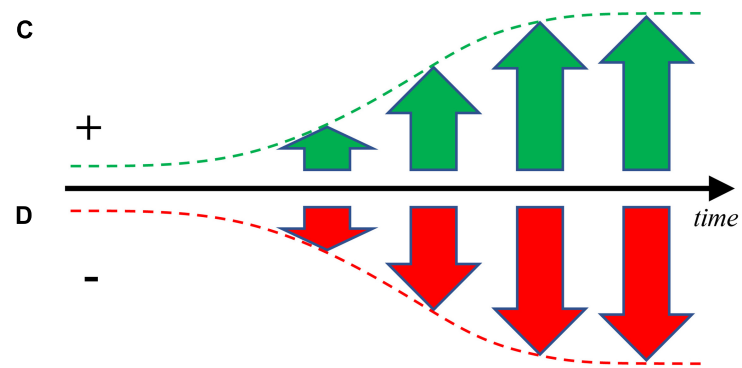

FIGURE 1 | Optogenetic manipulation of seizure propensity. (A) Optogenetics can be used to drive seizures acutely (Khoshkhoo et al., 2017) or to (B) put a brake on already active seizures (Wykes et al., 2012; Krook-Magnuson et al., 2013) as a form of pro- or anti-convulsant, respectively. This latter approach has potential clinical applications for interrupting ongoing seizures (Paz et al., 2013), whereas both are useful for studying epilepsy. (C) Seizures can also be gradually elicited over time via optogenetic kindling, or optokindling (Cela et al., 2019). Optokindling is fundamentally distinct from directly driving seizures by optogenetic stimulation, since optokindling requires long-lasting changes of neuronal circuits (Cela et al., 2019), whereas direct optogenetic drive does not (Khoshkhoo et al., 2017). (D) It may also be possible to gradually decrease seizure propensity via optogenetic dekindling. As far as we know, this remains to be experimentally demonstrated optogenetically, but such findings have been reported with electrical stimulation (Bains et al., 1999; Ozen and Teskey, 2009). The kindling and dekindling modes may both enable the study of epileptogenesis, e.g. to test therapies that slow down or reverse the development of seizures.

linked to both the initial seizure activity (Khoshkhoo et al., 2017) and eventual generalization of seizures (Wang et al., 2017). In a handful of pioneering studies, it was shown that spontaneous seizures in a TLE induction model can be controlled by either stimulation of GABAergic cells or direct optogenetic inhibition of PCs in the hippocampus (Krook-Magnuson et al., 2013; Ladas et al., 2015; Lu et al., 2016). Inhibiting excitatory PCs using NpHR to stop or alleviate seizures has also been shown in hippocampus (Tonnesen et al., 2009; Sukhotinsky et al., 2013; Berglind et al., 2014; Krook-Magnuson et al., 2015). Finally, it was found that stroke-induced seizures can be stopped using optogenetic inhibition of thalamocortical neurons via $\mathrm{NpHR}$ (Paz et al., 2013).

However, inhibition is not always local. For example, it has been shown that TLE seizures can be inhibited by optogenetically stimulating the cerebellum (Krook-Magnuson et al., 2014). TLE seizure generalization is modulated differently by mossy and granule cells and these seizures are correlated with decreased spatial discrimination performance, mirroring similar deficits in human epilepsies (Bui et al., 2018). In another study, researchers used inhibitory opsins to suppress PC activity and abort seizures in a tetanus-toxin-induced model of neocortical epilepsy (Wykes et al., 2012). High-frequency light stimulation was both shown to inhibit 4-AP-induced seizures in vivo and in vitro (Chiang et al., 2014). Finally, seizure suppression has also been achieved in dorsal raphe and superior colliculus, highlighting the utility of optogenetics across several brain areas (Soper et al., 2016; Zhang H. H. et al., 2018).

Optogenetics has also been used to modulate seizures arising in genetic models where animals have a predilection to developing seizures. In absence epilepsy models, both activation of tonic spiking in thalamus and optogenetic stimulation of cerebellar neurons abated seizures in vivo (Kros et al., 2015; Sorokin et al., 2017). Taken together, these studies highlight different ways optogenetics can be used for seizure cessation, to potentially enable therapeutic treatments.

\section{Promoting Seizures With Optogenetics}

Optogenetics has also been used to study the initiation of seizures and contributions of different cell types to seizure activity (Figure 1). Several studies have been able to induce seizures using only light stimulation. For example, stimulation of ChR2-expressing cells in the hippocampus led to seizurelike events (Osawa et al., 2013). Optogenetic stimulation of hippocampal PCs can also give rise to progressively intense seizures (Berglind et al., 2018). High-frequency optogenetic stimulation of PCs in dorsal or intermediate hippocampus give rise to different behaviors such as face twitching or clonus providing an explanation for the heterogeneity of seizure types seen in patients with hippocampal pathology (Weitz et al., 2015). Another study found kindling-like effects after optogenetic stimulation of dentate gyrus, in the form of increased in duration and severity of seizure responses (Krook-Magnuson et al., 2015).

PCs are not the only neurons participating in seizure activity, INs have been also implicated on different aspects of seizure formation. For example, activation of PV INs can induce seizures during the inter-ictal period but inhibit them during the ictal period (Assaf and Schiller, 2016). Further, optogenetic induction of seizures in neocortex revealed different roles of distinct IN populations with VIP inhibition increasing seizure threshold and somatostatin (SOM) and parvalbumin (PV) prolonging seizures during ictal activity (Khoshkhoo et al., 2017). Indeed, INs may play a role in the transition to ictal events through rebound excitation (Chang et al., 2018). Thus, seizure onset is not determined solely by PCs; it is increasingly recognized that certain IN populations such as VIP play a key role (Khoshkhoo et al., 2017).

Promoting seizures with optogenetics does not have to rely on light stimulation alone. Indeed, several studies took advantage of the established electrical kindling protocol and used it in parallel with light stimulation to investigate epileptogenesis (Wang et al., 2017; Berglind et al., 2018). Using light stimulation 
alone eliminates the amount of damage caused by the stimulating electrode during electrical kindling and allows optogenetic targeting of diverse cell populations to study the breadth of epilepsies occurring.

While optogenetic stimulation alone has been proven sufficient in several cases (Osawa et al., 2013; Khoshkhoo et al., 2017; Cela et al., 2019), many studies use a genetic model or chemical proconvulsants in conjunction with optogenetics. For example, light stimulation of somatosensory cortex of mice with genetic mutations increasing susceptibility to absence epilepsy also initiates seizure events (Wagner et al., 2015). In addition, electrical kindling can be combined with optogenetic stimulation to give rise to progressively worsening generalized seizures (Wang et al., 2017). Another study exploring the graded development of seizures in hippocampus following repeated light stimulation found progressively worsening and eventual spread of seizure activity (Berglind et al., 2018). These studies showed that optogenetic stimulation is sufficient to induce seizures, but more work remains to be done using long-term stimulation as well as monitoring additional seizure properties in awake behaving animals.

Furthermore, several recent studies using optogenetics to investigate the contribution of different neuronal population to seizures have reported conflicting results. In CA3 for example, optogenetic activation of PV INs led to excitatory GABA transmission and a boost of seizure activity (Ellender et al., 2014). In apparent contradiction, activation of GABA INs in the subiculum delayed generalized seizures after TLE (Wang et al., 2017). In addition, optogenetic PV IN activation leads to ictal discharges in vitro (Shiri et al., 2015) as well as during 4-AP application (Yekhlef et al., 2015). However, a previous study using ChR2 to activate PV cells near the seizure focus led to cessation of seizures (Sessolo et al., 2015). During ongoing ictal activity, raised intraneuronal chloride levels may contribute to depolarizing GABA responses, further promoting both spontaneous and optogenetically elicited seizures (Cohen et al., 2002; Timofeev et al., 2002; Staley, 2004; Magloire et al., 2019), an effect that depends on KCC2 (Silayeva et al., 2015; Magloire et al., 2019). These conflicting results relied on optogenetics to highlight the complexity of IN contribution to seizure dynamics and underscore the need for further study. Future studies would benefit from looking at other IN types such as VIP and SOM to investigate the relative contribution of different IN populations to seizure formation.

\section{Optogenetic Kindling Models of Epilepsy}

Multiple studies have shown that seizures can be acutely elicited with optogenetics (Table $\mathbf{1}$ and Figure 1). In light of this, is there a place for using optokindling? We argue that there are several key advantages. Because optokindling allows graded development, increased severity of electrographic and behavioral seizures over time, as well as long-term susceptibility of seizure properties akin to long-term memory (Table 2; Goddard, 1967; Teskey, 2001), it is possible to use optokindling to study aspects of epileptogenesis rather than simply studying directly driven seizures. These features make kindling a reliable animal model
TABLE 2 | Hallmark features of kindling.

\begin{tabular}{lll}
\hline \multicolumn{1}{c}{ Metric } & Description \\
\hline 1 & $\begin{array}{l}\text { Electrogenic } \\
\text { seizure severity }\end{array}$ & $\begin{array}{l}\text { Kindling causes an increase in duration, amplitude, } \\
\text { frequency, and complexity of seizures. } \\
\text { Behavioral seizures appear and increase in severity. }\end{array}$ \\
2 & $\begin{array}{l}\text { Behavioral } \\
\text { seizure severity } \\
3\end{array}$ & Seizure threshold \\
4 & $\begin{array}{l}\text { Seizure } \\
\text { propagation }\end{array}$ & $\begin{array}{l}\text { Seizure threshold is reduced, so that initially inert } \\
\text { stimulation may eventually elicit seizures. } \\
\text { Seizure eventually propagates from stimulation site to } \\
\text { distant brain regions. }\end{array}$
\end{tabular}

Key properties of kindling, as outlined by Teskey (2001).

for the study of the transition to seizures from a healthy brain over the long term (Sato et al., 1990).

Additionally, kindling can be combined with a second factor in a two-hit model of seizures to examine synergistic effects (Berkovic et al., 2006). For example, the two-hit model can be used to study how early-life seizures impinge on seizure propensity later in life (Koh et al., 2001).

With these advantages in mind, we recently developed an optokindling model in neocortex that replicated several hallmark features of electrical kindling (Table 2), including gradual seizure development as well as long-term seizure retention (Cela et al., 2019). With optokindling, we were able to induce seizures (Figure 2) whilst avoiding tissue damage (Cela et al., 2019), which might otherwise confound interpretation of results (Pitkänen et al., 2009). We found that optokindling could mimic the gradual development of seizures in epileptogenesis (Morrell, 1985), as an initially inert stimulus eventually elicited electrographic (Figure 2) as well as behavioral seizures (Cela et al., 2019).

Going forward, in order to effectively develop optogenetic variants to classical kindling, classical changes accompanying kindling must be measured such as long-term retention of seizure susceptibility, worsening electrographic and behavioral seizures, as well as changes in seizure threshold and possible propagation of seizures (Table 2; Goddard et al., 1969; Teskey, 2001). These variables are critical to differentiate optokindling models from direct optogenetic drive of seizures (also see Table 1).

Furthermore, optogenetics also opens up new avenues of examining dekindling, or the gradual decrease in seizure propensity, i.e. the opposite of epileptogenesis (Figure 1; Morrell, 1960; Salanova et al., 1996). With optogenetics, it may be possible to reverse the synaptic changes occurring during epileptogenesis. Future studies also need to examine other brain areas aside from neocortex to ensure that the optokindling effect can be replicated elsewhere in the brain as was done with electrical kindling (Goddard et al., 1969; Cela et al., 2019).

\section{FUTURE DIRECTIONS AND CONCLUSION}

Over several decades, the field of epilepsy has benefited from multiple animal models of epilepsy, as described above. More recently, optogenetics has been used to study epilepsy with the goal of linking circuit properties to seizures in defined neuronal 
A

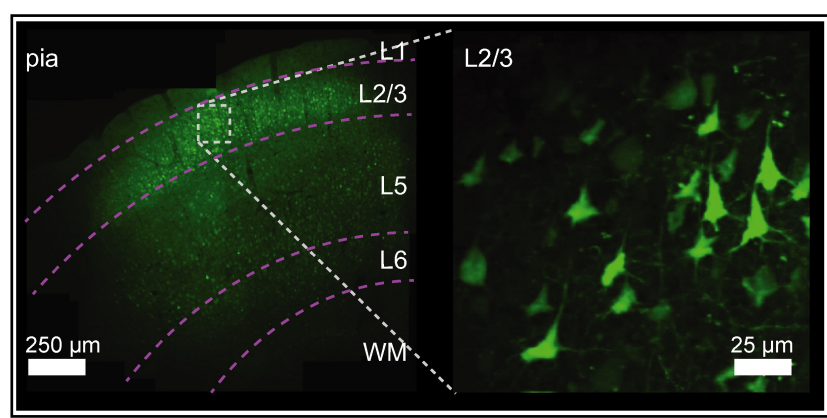

B

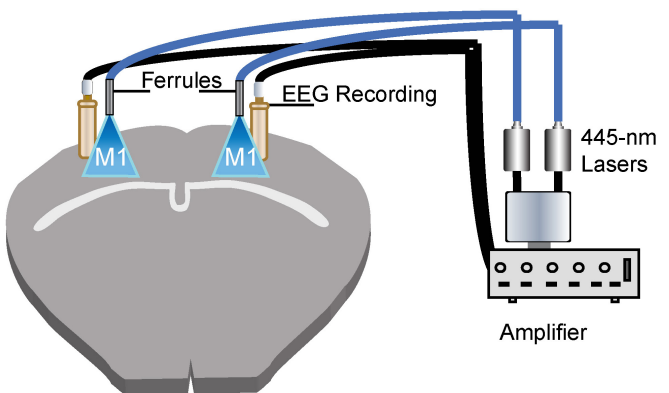

Session 1

C
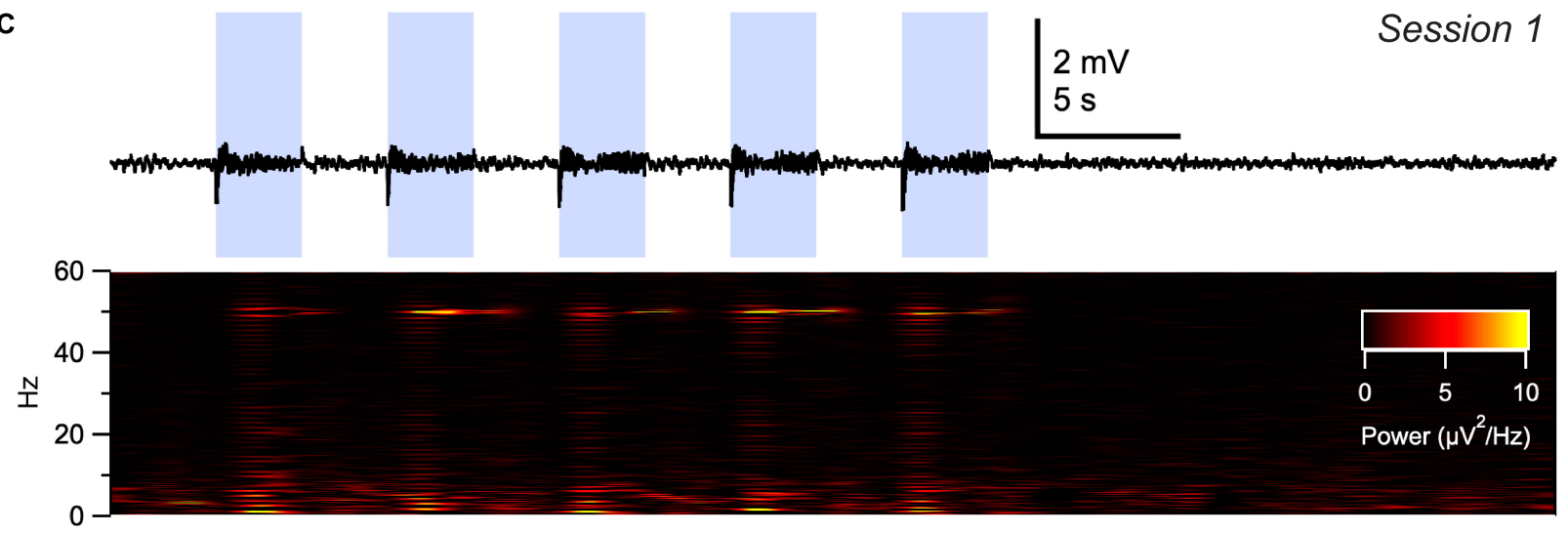

D
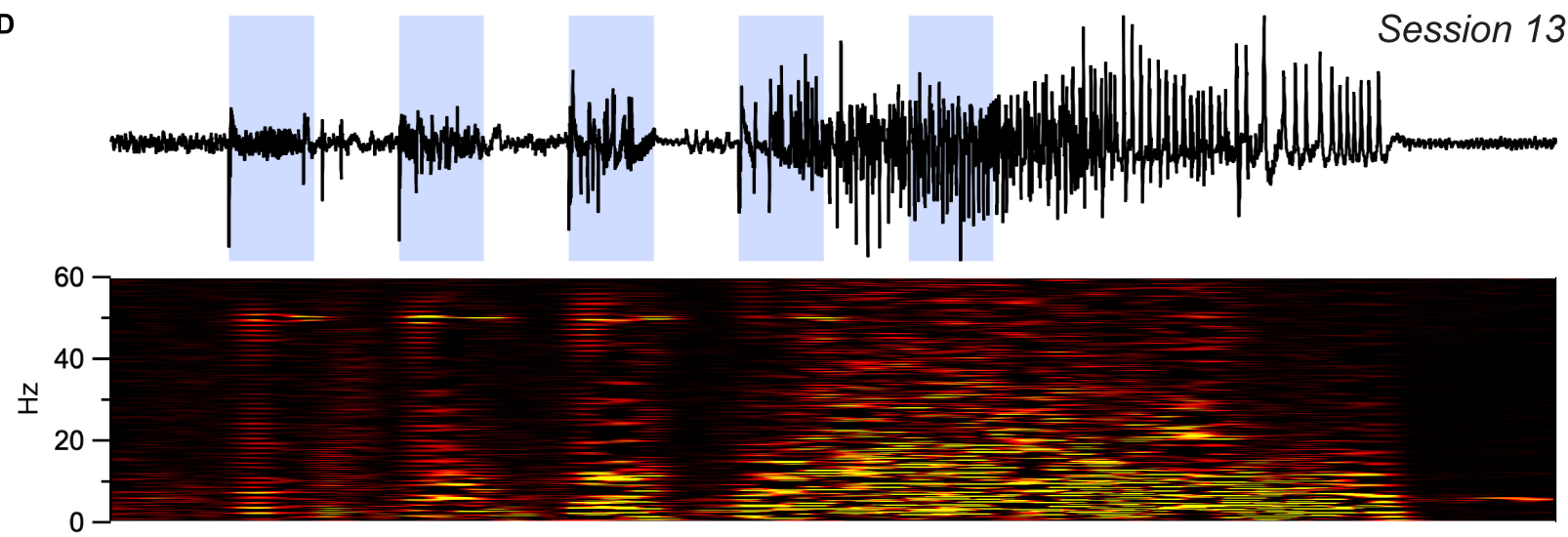

FIGURE 2 | Optokindling via simultaneous EEG recording and ChR2 stimulation in awake behaving animals. (A) Coronal M1 section immunostained for EYFP indicated ChR2 expression in layer 2/3 (L2/3), 5, and 6, though predominantly in L2/3. Inset shows close-up of L2/3 ChR2-expressing PCs. (B) To simultaneously activate ChR2 and acquire EEG, ferrules and recording screws were implanted bilaterally above M1, without penetrating the cortex. Fiber optic cables were air-coupled to 445-nm lasers. EEG signals were processed by an extracellular amplifier, but not pre-amplified. A computer (not shown) TTL-gated the lasers and digitized amplified EEG signals. (C) Sample EEG trace illustrating that M1 optokindling did not elicit seizures in stimulation session 1 of 25 (Top). Spectrogram shows direct light-driven responses in the 50-Hz band but no seizures (Bottom). (D) M1 optokindling in session 13 elicited a prominent seizure in this sample EEG sweep (Top). Spectrogram reveals both light-driven responses in the $50-\mathrm{Hz}$ band as well as increased power in low-frequency bands (Bottom). Reproduced and modified from Figure 1 in Cela et al. (2019), with permission.

populations. Here, we have discussed how optogenetics was used to both activate and inactivate target cells leading to either prolonging or reducing seizure duration in several different brain regions (Table 1).

However, several issues remain before optogenetics will likely gain widespread use in epilepsy research. First the virus injection and ferrule implantation procedure that is required for optogenetic activation is time consuming and labor intensive. This has already begun to be addressed by near infrared (IR) versions of ChR2 which do not need ferrule implants for light delivery and can instead be activated transcranially (Lin et al., 2013). These IR variants also reduce the possibility of heat-induced light damage from prolonged stimulation 
(Christie et al., 2013; Hososhima et al., 2015). Secondly, the EEG recording, which also requires time-consuming implantation procedures, can be replaced by all-optical interrogation of neural circuits using genetically encoded sensors for readout and optogenetic actuators for control of cellular activity (Emiliani et al., 2015). Thirdly, the advantage of optogenetics in targeting different neuronal populations is restricted by the specificity of factors such as promoters and viral serotype.

As the genetic toolkit for exogenous protein expression continues to expand (Sjulson et al., 2016), it will allow for the activity of neural circuits contributing to seizure formation to be recorded and manipulated by light, which in turn will enable the development of novel epilepsy models with improved spatiotemporal precision (Zhang Z. et al., 2018). This will likely be particularly useful in closed-loop systems where real-time adjustment can be made based on behavior or ongoing brain activity, e.g. at the start of seizures to shut them down.

Optokindling is a particular subset of this genetic toolkit studies such as ours (Cela et al., 2019) will hopefully improve our understanding of circuit changes in epileptogenesis rather than of acute seizure induction. This is important since longterm seizure development may closely mimic certain aspects of human epilepsies that involve circuit alterations while acute seizures models may be more useful to study circuits and seizure properties as such (Sutula, 2004; Lillis et al., 2015).

Optogenetics is not the only genetic neuronal activation system useful for the study of epilepsy. Another system that has been used is pharmacogenetics using designer receptors exclusively activated by designer drugs (DREADDS). DREADDS are G-coupled receptors and can be used to inhibit (hMD4i receptor) or excite (hM3Dq receptor) cells (Pei et al., 2008) upon addition of the drug clozapine $\mathrm{N}$-oxide (CNO). DREADDS have been used to both halt and initiate seizure development, e.g. seizure suppression in organotypic hippocampal slice cultures (Avaliani et al., 2016), seizure blockade in amygdala-kindled mice (Wicker and Forcelli, 2016), as well as silencing of pilocarpineinduced seizures in vivo (Katzel et al., 2014).

A recent study has highlighted the possibility of using optogenetics along with pharmacogenetics to induce seizures with the former while abating their activity with the latter (Berglind et al., 2018). DREADDS can be used to chronically inhibit or promote activity in genetically defined neurons similar to optogenetics but while DREADDS can serve some of the main properties of optogenetics in studying seizures, they have significant disadvantages. First, DREADDS have reduced temporal specificity compared to optogenetics. Chronic manipulation of activity levels imposed by DREADDS lack the millisecond-scale precision mimicking synaptic transmission afforded by optogenetics. Second, the supposedly otherwise inert agonist (CNO) can in fact be metabolized back to clozapine and have off-target effects such as lowered seizure threshold, which could of course cloud the interpretation in epilepsy studies (Sajatovic and Meltzer, 1996; Manvich et al., 2018). Optogenetics may thus prove to be a better method of activity manipulation when studying seizure initiation. However, when it comes to seizure control, DREADDS may be advantageous due to the steady modulation of excitability that they provide without the need for repeated intervention, as is the case for optogenetics.

In conjunction with genetic methods for manipulating neuronal activity, the roles of injury and inflammation can be explored using the two-hit model (Berkovic et al., 2006). Optical induction models such as optokindling have a narrower focus on activity-dependent plasticity, since - compared to their electric or chemical counterparts - they result in relatively little tissue damage or inflammation (Cela et al., 2019). It may in fact be possible to optokindle transgenic mice without the need for viral injection or surgery (Cela et al., 2019), thus bypassing injury and inflammation completely. This may make them especially useful for discovering novel therapies, to halt or slow down pathological plasticity in epileptogenesis.

The application of optogenetic intervention in human epilepsies has been delayed because several hurdles need to be overcome. For example, there are health concerns associated with using viral vectors for gene delivery. Furthermore, the human brain is much larger than that of rodents, which means much more powerful light sources are required to access deep brain structures (Couzin and Kaiser, 2005; Delbeke et al., 2017). Furthermore, optogenetic seizure interruption requires highly accurate real-time seizure detection, which is still a largely unsolved issue (Dheer et al., 2017). Nonetheless, there are several avenues for anti-epileptic optogenetic intervention in humans. For example, MRI-compatible fiber optrodes can be used to suppress seizures after injection of AAV-NpHR in epileptic tissue (Duffy et al., 2015).

Although it remains unknown what precisely the future holds in store, what should be clear from this review is that optogenetics is here to stay as a key tool to control activity in primary epilepsy research as well as in future treatments. Recent optogenetic studies have already revealed e.g. the differential IN population role in seizure initiation as well as different ways of halting seizures depending on the brain area (Paz et al., 2013; Ellender et al., 2014; Khoshkhoo et al., 2017). With optogenetics, additional circuit components underlying seizures will be dissected and novel therapeutic interventions will be discovered.

\section{AUTHOR CONTRIBUTIONS}

Both authors wrote the manuscript.

\section{FUNDING}

This work was supported by CIHR PG 389378 (PS) and FRQS CB Sr 254033 (PS).

\section{ACKNOWLEDGMENTS}

We thank Alanna Watt, Keith Murai, Hovy Wong, Airi Watanabe, Ibrahim Kays, Aurore Thomazeau, and Amanda McFarlan for their help and useful discussions. 


\section{REFERENCES}

Abrahamsson, T., Chou, C. Y. C., Li, S. Y., Mancino, A., Costa, R. P., Brock, J. A., et al. (2017). Differential regulation of evoked and spontaneous release by presynaptic NMDA receptors. Neuron 96, 839-855.e5. doi: 10.1016/j.neuron. 2017.09.030

Airan, R. D., Thompson, K. R., Fenno, L. E., Bernstein, H., and Deisseroth, K. (2009). Temporally precise in vivo control of intracellular signalling. Nature 458, 1025-1029. doi: 10.1038/nature07926

Alger, B. E. (2004). Endocannabinoids and their implications for epilepsy. Epilepsy Curr. 4, 169-173. doi: 10.1111/j.1535-7597.2004.04501.x

Assaf, F., and Schiller, Y. (2016). The antiepileptic and ictogenic effects of optogenetic neurostimulation of PV-expressing interneurons. J. Neurophysiol. 116, 1694-1704. doi: 10.1152/jn.00744.2015

Avaliani, N., Andersson, M., Runegaard, A. H., Woldbye, D., and Kokaia, M. (2016). DREADDs suppress seizure-like activity in a mouse model of pharmacoresistant epileptic brain tissue. Gene Ther. 23, 760-766. doi: 10.1038/ gt.2016.56

Bains, J. S., Longacher, J. M., and Staley, K. J. (1999). Reciprocal interactions between CA3 network activity and strength of recurrent collateral synapses. Nat. Neurosci. 2, 720-726. doi: 10.1038/11184

Ben-Ari, Y., Crepel, V., and Represa, A. (2008). Seizures beget seizures in temporal lobe epilepsies: the boomerang effects of newly formed aberrant kainatergic synapses. Epilepsy Curr. 8, 68-72. doi: 10.1111/j.1535-7511.2008.00241.x

Berglind, F., Andersson, M., and Kokaia, M. (2018). Dynamic interaction of local and transhemispheric networks is necessary for progressive intensification of hippocampal seizures. Sci. Rep. 8:5669. doi: 10.1038/s41598-018-23659-x

Berglind, F., Ledri, M., Sorensen, A. T., Nikitidou, L., Melis, M., Bielefeld, P., et al. (2014). Optogenetic inhibition of chemically induced hypersynchronized bursting in mice. Neurobiol. Dis. 65, 133-141. doi: 10.1016/j.nbd.2014.01.015

Berkovic, S. F., Mulley, J. C., Scheffer, I. E., and Petrou, S. (2006). Human epilepsies: interaction of genetic and acquired factors. Trends Neurosci. 29, 391-397. doi: 10.1016/j.tins.2006.05.009

Bernard, C., Anderson, A., Becker, A., Poolos, N. P., Beck, H., and Johnston, D. (2004). Acquired dendritic channelopathy in temporal lobe epilepsy. Science 305, 532-535. doi: 10.1126/science. 1097065

Berndt, A., Lee, S. Y., Ramakrishnan, C., and Deisseroth, K. (2014). Structureguided transformation of channelrhodopsin into a light-activated chloride channel. Science 344, 420-424. doi: 10.1126/science.1252367

Boyden, E. S., Zhang, F., Bamberg, E., Nagel, G., and Deisseroth, K. (2005). Millisecond-timescale, genetically targeted optical control of neural activity. Nat. Neurosci. 8, 1263-1268. doi: 10.1038/nn1525

Brodie, M. J., Elder, A. T., and Kwan, P. (2009). Epilepsy in later life. Lancet Neurol. 8, 1019-1030. doi: 10.1016/S1474-4422(09)70240-6

Buchholz, F., Angrand, P. O., and Stewart, A. F. (1998). Improved properties of FLP recombinase evolved by cycling mutagenesis. Nat. Biotechnol. 16, 657-662. doi: $10.1038 /$ nbt0798-657

Bui, A. D., Nguyen, T. M., Limouse, C., Kim, H. K., Szabo, G. G., Felong, S., et al. (2018). Dentate gyrus mossy cells control spontaneous convulsive seizures and spatial memory. Science 359, 787-790. doi: 10.1126/science.aan4074

Burger, C., Gorbatyuk, O. S., Velardo, M. J., Peden, C. S., Williams, P., Zolotukhin, S., et al. (2004). Recombinant AAV viral vectors pseudotyped with viral capsids from serotypes 1,2 , and 5 display differential efficiency and cell tropism after delivery to different regions of the central nervous system. Mol. Ther. 10, 302-317. doi: 10.1016/j.ymthe.2004.05.024

Cain, D. P. (1981). Transfer of pentylenetetrazol sensitization to amygdaloid kindling. Pharmacol. Biochem. Behav. 15, 533-536. doi: 10.1016/0091-3057(81) 90202-1

Cain, D. P. (1983). Bidirectional transfer of electrical and carbachol kindling. Brain Res. 260, 135-138. doi: 10.1016/0006-8993(83)90774-6

Cain, D. P. (1989). Long-term potentiation and kindling: how similar are the mechanisms? Trends Neurosci. 12, 6-10. doi: 10.1016/0166-2236(89)90146-X

Cavalheiro, E. A., Leite, J. P., Bortolotto, Z. A., Turski, W. A., Ikonomidou, C., and Turski, L. (1991). Long-term effects of pilocarpine in rats: structural damage of the brain triggers kindling and spontaneous recurrent seizures. Epilepsia 32, 778-782. doi: 10.1111/j.1528-1157.1991.tb05533.x

Cavazos, J. E., Das, I., and Sutula, T. P. (1994). Neuronal loss induced in limbic pathways by kindling: evidence for induction of hippocampal sclerosis by repeated brief seizures. J. Neurosci. 14, 3106-3121. doi: 10.1523/jneurosci.1405-03106.1994

Cela, E., Mcfarlan, A. R., Chung, A. J., Wang, T., Chierzi, S., Murai, K. K., et al. (2019). An optogenetic kindling model of neocortical epilepsy. Sci. Rep. 9:5236. doi: 10.1038/s41598-019-41533-2

Chang, B. S., and Lowenstein, D. H. (2003). Epilepsy. N. Engl. J. Med. 349, 1257-1266.

Chang, M., Dian, J. A., Dufour, S., Wang, L., Moradi Chameh, H., Ramani, M., et al. (2018). Brief activation of GABAergic interneurons initiates the transition to ictal events through post-inhibitory rebound excitation. Neurobiol. Dis. 109, 102-116. doi: 10.1016/j.nbd.2017.10.007

Chatterjee, S., Sullivan, H. A., Maclennan, B. J., Xu, R., Hou, Y., Lavin, T. K., et al. (2018). Nontoxic, double-deletion-mutant rabies viral vectors for retrograde targeting of projection neurons. Nat. Neurosci. 21, 638-646. doi: 10.1038/ s41593-018-0091-7

Chauvette, S., Soltani, S., Seigneur, J., and Timofeev, I. (2015). In vivo models of cortical acquired epilepsy. J. Neurosci. Methods 260, 185-201. doi: 10.1016/j. jneumeth.2015.08.030

Chen, S., Weitemier, A. Z., Zeng, X., He, L., Wang, X., Tao, Y., et al. (2018). Near-infrared deep brain stimulation via upconversion nanoparticle-mediated optogenetics. Science 359, 679-684. doi: 10.1126/science.aaq1144

Chen, Z., Brodie, M. J., Liew, D., and Kwan, P. (2018). Treatment outcomes in patients with newly diagnosed epilepsy treated with established and new antiepileptic drugs: a 30-year longitudinal cohort study. JAMA Neurol. 75, 279-286. doi: 10.1001/jamaneurol.2017.3949

Chiang, C. C., Ladas, T. P., Gonzalez-Reyes, L. E., and Durand, D. M. (2014). Seizure suppression by high frequency optogenetic stimulation using in vitro and in vivo animal models of epilepsy. Brain Stimul. 7, 890-899. doi: 10.1016/j. brs.2014.07.034

Chow, B. Y., Han, X., Dobry, A. S., Qian, X., Chuong, A. S., Li, M., et al. (2010). High-performance genetically targetable optical neural silencing by light-driven proton pumps. Nature 463, 98-102. doi: 10.1038/nature08652

Christie, I. N., Wells, J. A., Southern, P., Marina, N., Kasparov, S., Gourine, A. V., et al. (2013). fMRI response to blue light delivery in the naive brain: implications for combined optogenetic fMRI studies. Neuroimage 66, 634-641. doi: 10.1016/j.neuroimage.2012.10.074

Chuong, A. S., Miri, M. L., Busskamp, V., Matthews, G. A., Acker, L. C., Sorensen, A. T., et al. (2014). Noninvasive optical inhibition with a red-shifted microbial rhodopsin. Nat. Neurosci. 17, 1123-1129. doi: 10.1038/nn.3752

Clark, M., Post, R. M., Weiss, S. R., and Nakajima, T. (1992). Expression of c-fos mRNA in acute and kindled cocaine seizures in rats. Brain Res. 582, 101-106. doi: 10.1016/0006-8993(92)90322-z

Cohen, I., Navarro, V., Clemenceau, S., Baulac, M., and Miles, R. (2002). On the origin of interictal activity in human temporal lobe epilepsy in vitro. Science 298, 1418-1421. doi: 10.1126/science.1076510

Couzin, J., and Kaiser, J. (2005). Gene therapy. As Gelsinger case ends, gene therapy suffers another blow. Science 307:1028.

Delbeke, J., Hoffman, L., Mols, K., Braeken, D., and Prodanov, D. (2017). And then there was light: perspectives of optogenetics for deep brain stimulation and neuromodulation. Front. Neurosci. 11:663. doi: 10.3389/fnins.2017.00663

Dheer, P., Chaitanya, G., Pizarro, D., Esteller, R., Majumdar, K., and Pati, S. (2017). Seizure detection and network dynamics of generalized convulsive seizures: towards rational designing of closed-loop neuromodulation. Neurosci. J. 2017:9606213. doi: 10.1155/2017/9606213

Di Maio, R., Colangeli, R., and Di Giovanni, G. (2019). WIN 55,212-2 reverted pilocarpine-induced status epilepticus early changes of the interaction among 5-HT2C/NMDA/CB1 receptors in the rat hippocampus. ACS Chem. Neurosci. 10, 3296-3306. doi: 10.1021/acschemneuro.9b00080

Dittgen, T., Nimmerjahn, A., Komai, S., Licznerski, P., Waters, J., Margrie, T. W., et al. (2004). Lentivirus-based genetic manipulations of cortical neurons and their optical and electrophysiological monitoring in vivo. Proc. Natl. Acad. Sci. U.S.A. 101, 18206-18211. doi: 10.1073/pnas.0407976101

Duffy, B. A., Choy, M., Chuapoco, M. R., Madsen, M., and Lee, J. H. (2015). MRI compatible optrodes for simultaneous LFP and optogenetic fMRI investigation of seizure-like afterdischarges. Neuroimage 123, 173-184. doi: 10.1016/j. neuroimage.2015.07.038

Dymecki, S. M., and Kim, J. C. (2007). Molecular neuroanatomy's "Three Gs": a primer. Neuron 54, 17-34. doi: 10.1016/j.neuron.2007.03.009 
Ellender, T. J., Raimondo, J. V., Irkle, A., Lamsa, K. P., and Akerman, C. J. (2014). Excitatory effects of parvalbumin-expressing interneurons maintain hippocampal epileptiform activity via synchronous afterdischarges. J. Neurosci. 34, 15208-15222. doi: 10.1523/JNEUROSCI.1747-14.2014

Emiliani, V., Cohen, A. E., Deisseroth, K., and Häusser, M. (2015). All-optical interrogation of neural circuits. J. Neurosci. 35, 13917-13926. doi: 10.1523/ JNEUROSCI.2916-15.2015

Engel, J. (2005). Epilepsy: Global Issues for the Practicing Neurologist. New York, NY: Demos Medical Pub.

Engel, J., and Pedley, T. A. (2008). Epilepsy: A Comprehensive Textbook. Philadelphia, PA: Wolters Kluwer Health.

Fisher, R. S. (1989). Animal models of the epilepsies. Brain Res. Brain Res. Rev. 14, 245-278. doi: 10.1016/0165-0173(89)90003-9

Fisher, R. S., Acevedo, C., Arzimanoglou, A., Bogacz, A., Cross, J. H., Elger, C. E., et al. (2014). ILAE official report: a practical clinical definition of epilepsy. Epilepsia 55, 475-482. doi: 10.1111/epi.12550

Fisher, R. S., van Emde Boas, W., Blume, W., Elger, C., Genton, P., Lee, P., et al. (2005). Epileptic seizures and epilepsy: definitions proposed by the international league against epilepsy (ILAE) and the international bureau for epilepsy (IBE). Epilepsia 46, 470-472. doi: 10.1111/j.0013-9580.2005.66104.x

Fitzsimons, H. L., Bland, R. J., and During, M. J. (2002). Promoters and regulatory elements that improve adeno-associated virus transgene expression in the brain. Methods 28, 227-236. doi: 10.1016/s1046-2023(02)00227-x

Gilbert, M. E. (1992). Proconvulsant activity of endosulfan in amygdala kindling. Neurotoxicol. Teratol. 14, 143-149. doi: 10.1016/0892-0362(92)90 062-f

Glasscock, E., Qian, J., Yoo, J. W., and Noebels, J. L. (2007). Masking epilepsy by combining two epilepsy genes. Nat. Neurosci. 10, 1554-1558. doi: 10.1038/ nn1999

Goddard, G. V. (1967). Development of epileptic seizures through brain stimulation at low intensity. Nature 214, 1020-1021. doi: 10.1038/2141020a0

Goddard, G. V., Mcintyre, D. C., and Leech, C. K. (1969). A permanent change in brain function resulting from daily electrical stimulation. Exp. Neurol. 25, 295-330. doi: 10.1016/0014-4886(69)90128-9

Gottschalk, S., Fehm, T. F., Deán-Ben, X. L., Tsytsarev, V., and Razansky, D. (2016). Correlation between volumetric oxygenation responses and electrophysiology identifies deep thalamocortical activity during epileptic seizures. Neurophotonics 4:011007. doi: 10.1117/1.nph.4.1.011007

Grabenstatter, H. L., Del Angel, Y. C., Carlsen, J., Wempe, M. F., White, A. M., Cogswell, M., et al. (2014). The effect of STAT3 inhibition on status epilepticus and subsequent spontaneous seizures in the pilocarpine model of acquired epilepsy. Neurobiol. Dis. 62, 73-85. doi: 10.1016/j.nbd.2013.09.003

Gradinaru, V., Zhang, F., Ramakrishnan, C., Mattis, J., Prakash, R., Diester, I., et al. (2010). Molecular and cellular approaches for diversifying and extending optogenetics. Cell 141, 154-165. doi: 10.1016/j.cell.2010.02.037

Harz, H., and Hegemann, P. (1991). Rhodopsin-regulated calcium currents in chlamydomonas. Nature 351, 489-491. doi: 10.1038/351489a0

Herman, S. T. (2002). Epilepsy after brain insult: targeting epileptogenesis. Neurology 59, S21-S26.

Hopkins, D. A., and Holstege, G. (1978). Amygdaloid projections to the mesencephalon, pons and medulla oblongata in the cat. Exp. Brain Res. 32, 529-547.

Hososhima, S., Yuasa, H., Ishizuka, T., Hoque, M. R., Yamashita, T., Yamanaka, A., et al. (2015). Near-infrared (NIR) up-conversion optogenetics. Sci. Rep. 5:16533. doi: 10.1038/srep 16533

Inoue, K., Ono, H., Abe-Yoshizumi, R., Yoshizawa, S., Ito, H., Kogure, K., et al. (2013). A light-driven sodium ion pump in marine bacteria. Nat. Commun. 4:1678. doi: $10.1038 /$ ncomms 2689

Ishiura, H., Doi, K., Mitsui, J., Yoshimura, J., Matsukawa, M. K., Fujiyama, A., et al. (2018). Expansions of intronic TTTCA and TTTTA repeats in benign adult familial myoclonic epilepsy. Nat. Genet. 50, 581-590. doi: 10.1038/s41588-0180067-2

Katzel, D., Nicholson, E., Schorge, S., Walker, M. C., and Kullmann, D. M. (2014). Chemical-genetic attenuation of focal neocortical seizures. Nat. Commun. 5:3847. doi: 10.1038/ncomms4847

Khoshkhoo, S., Vogt, D., and Sohal, V. S. (2017). Dynamic, cell-type-specific roles for GABAergic interneurons in a mouse model of optogenetically inducible seizures. Neuron 93, 291-298. doi: 10.1016/j.neuron.2016.11.043
Kogure, S., Kitayama, M., and Matsuda, Y. (2000). Simultaneous kindling of the bilateral hippocampi: an advanced model for epilepsy research. Epilepsia 41, 929-932. doi: 10.1111/j.1528-1157.2000.tb00274.x

Koh, S., Storey, T. W., Santos, T. C., Mian, A. Y., and Cole, A. J. (2001). Earlylife seizures in rats increase susceptibility to seizure-induced brain injury in adulthood. 1999. Neurology 57, S22-S28.

Krook-Magnuson, E., Armstrong, C., Bui, A., Lew, S., Oijala, M., and Soltesz, I. (2015). In vivo evaluation of the dentate gate theory in epilepsy. J. Physiol. 593, 2379-2388. doi: 10.1113/JP270056

Krook-Magnuson, E., Armstrong, C., Oijala, M., and Soltesz, I. (2013). On-demand optogenetic control of spontaneous seizures in temporal lobe epilepsy. Nat. Commun. 4:1376. doi: 10.1038/ncomms2376

Krook-Magnuson, E., Szabo, G. G., Armstrong, C., Oijala, M., and Soltesz, I. (2014). Cerebellar directed optogenetic intervention inhibits spontaneous hippocampal seizures in a mouse model of temporal lobe epilepsy. eNeuro 1:e.2014.

Kros, L., Eelkman Rooda, O. H., Spanke, J. K., Alva, P., Van Dongen, M. N., Karapatis, A., et al. (2015). Cerebellar output controls generalized spike-andwave discharge occurrence. Ann. Neurol. 77, 1027-1049. doi: 10.1002/ana. 24399

Kwan, P., and Brodie, M. J. (2000). Early identification of refractory epilepsy. N Engl. J. Med. 342, 314-319. doi: 10.1056/NEJM200002033420503

Kwan, P., Schachter, S. C., and Brodie, M. J. (2011). Drug-resistant epilepsy. New Engl. J. Med. 365, 919-926.

Ladas, T. P., Chiang, C. C., Gonzalez-Reyes, L. E., Nowak, T., and Durand, D. M. (2015). Seizure reduction through interneuron-mediated entrainment using low frequency optical stimulation. Exp. Neurol. 269, 120-132. doi: 10.1016/j. expneurol.2015.04.001

Lalanne, T., Oyrer, J., Mancino, A., Gregor, E., Chung, A., Huynh, L., et al. (2016). Synapse-specific expression of calcium-permeable AMPA receptors in neocortical layer 5. J. Physiol. 594, 837-861. doi: 10.1113/JP271394

Larsen, R. S., and Sjöström, P. J. (2015). Synapse-type-specific plasticity in local circuits. Curr. Opin. Neurobiol. 35, 127-135. doi: 10.1016/j.conb.2015. 08.001

Lenkov, D. N., Volnova, A. B., Pope, A. R., and Tsytsarev, V. (2013). Advantages and limitations of brain imaging methods in the research of absence epilepsy in humans and animal models. J. Neurosci. Methods 212, 195-202. doi: 10.1016/j. jneumeth.2012.10.018

Li, H., Chen, A., Xing, G., Wei, M. L., and Rogawski, M. A. (2001). Kainate receptor-mediated heterosynaptic facilitation in the amygdala. Nat. Neurosci. 4, 612-620. doi: 10.1038/88432

Libbrecht, S., Van Den Haute, C., Malinouskaya, L., Gijsbers, R., and Baekelandt, V. (2017). Evaluation of WGA-Cre-dependent topological transgene expression in the rodent brain. Brain Struct. Funct. 222, 717-733. doi: 10.1007/s00429-0161241-X

Lillis, K. P., Wang, Z., Mail, M., Zhao, G. Q., Berdichevsky, Y., Bacskai, B., et al. (2015). Evolution of network synchronization during early epileptogenesis parallels synaptic circuit alterations. J. Neurosci. 35, 9920-9934. doi: 10.1523/ JNEUROSCI.4007-14.2015

Lima, S. Q., and Miesenböck, G. (2005). Remote control of behavior through genetically targeted photostimulation of neurons. Cell 121, 141-152. doi: 10 . 1016/j.cell.2005.02.004

Lin, J. Y., Knutsen, P. M., Muller, A., Kleinfeld, D., and Tsien, R. Y. (2013). ReaChR: a red-shifted variant of channelrhodopsin enables deep transcranial optogenetic excitation. Nat. Neurosci. 16, 1499-1508. doi: 10.1038/nn.3502

Liu, Q., Bhat, M., Bowen, W. D., and Cheng, J. (2009). Signaling pathways from cannabinoid receptor-1 activation to inhibition of N-methyl-D-aspartic acid mediated calcium influx and neurotoxicity in dorsal root ganglion neurons. J. Pharmacol. Exp. Ther. 331, 1062-1070. doi: 10.1124/jpet.109.156216

Lo, L., and Anderson, D. J. (2011). A Cre-dependent, anterograde transsynaptic viral tracer for mapping output pathways of genetically marked neurons. Neuron 72, 938-950. doi: 10.1016/j.neuron.2011.12.002

Löscher, W. (2002). Animal models of epilepsy for the development of antiepileptogenic and disease-modifying drugs. A comparison of the pharmacology of kindling and post-status epilepticus models of temporal lobe epilepsy. Epilepsy Res. 50, 105-123. doi: 10.1016/s0920-1211(02)00073-6

Löscher, W. (2011). Critical review of current animal models of seizures and epilepsy used in the discovery and development of new antiepileptic drugs. Seizure 20, 359-368. doi: 10.1016/j.seizure.2011.01.003 
Lu, Y., Zhong, C., Wang, L. L., Wei, P. F., He, W., Huang, K., et al. (2016). Optogenetic dissection of ictal propagation in the hippocampal-entorhinal cortex structures. Nat. Commun. 7:10962. doi: 10.1038/ncomms10962

Magloire, V., Cornford, J., Lieb, A., Kullmann, D. M., and Pavlov, I. (2019). KCC2 overexpression prevents the paradoxical seizure-promoting action of somatic inhibition. Nat. Commun. 10:1225. doi: 10.1038/s41467-019-08933-4

Manvich, D. F., Webster, K. A., Foster, S. L., Farrell, M. S., Ritchie, J. C., Porter, J. H., et al. (2018). The DREADD agonist clozapine N-oxide (CNO) is reversemetabolized to clozapine and produces clozapine-like interoceptive stimulus effects in rats and mice. Sci. Rep. 8:3840. doi: 10.1038/s41598-018-22116-z

Masseck, O. A., Spoida, K., Dalkara, D., Maejima, T., Rubelowski, J. M., Wallhorn, L., et al. (2014). Vertebrate cone opsins enable sustained and highly sensitive rapid control of Gi/o signaling in anxiety circuitry. Neuron 81, 1263-1273. doi: 10.1016/j.neuron.2014.01.041

McEachern, J. C., and Shaw, C. A. (1999). The plasticity-pathology continuum: defining a role for the LTP phenomenon. J. Neurosci. Res. 58, 42-61. doi: 10.1002/(sici)1097-4547(19991001)58:1<42::aid-jnr6>3.3.co;2-c

Michael, M., Holsinger, D., Ikeda-Douglas, C., Cammisuli, S., Ferbinteanu, J., Desouza, C., et al. (1998). Development of spontaneous seizures over extended electrical kindling: I. Electrographic, behavioral, and transfer kindling correlates. Brain Res. 793, 197-211.

Mori, N., and Wada, J. A. (1989). Bidirectional transhemispheric interaction between amygdaloid kindling induced by excitatory amino-acids and electricalstimulation. Epilepsia 30, 271-275. doi: 10.1111/j.1528-1157.1989.tb05298.x

Morrell, F. (1960). Secondary epileptogenic lesions. Epilepsia 1, 538-560. doi: 10.1111/j.1528-1157.1959.tb04288.x

Morrell, F. (1985). Secondary epileptogenesis in man. Arch. Neurol. 42, 318-335. doi: 10.1001/archneur.1985.04060040028009

Nadler, J. V., Perry, B. W., and Cotman, C. W. (1978). Intraventricular kainic acid preferentially destroys hippocampal pyramidal cells. Nature 271, 676-677. doi: $10.1038 / 271676 \mathrm{a} 0$

Nagel, G., Ollig, D., Fuhrmann, M., Kateriya, S., Musti, A. M., Bamberg, E., et al. (2002). Channelrhodopsin-1: a light-gated proton channel in green algae. Science 296, 2395-2398. doi: 10.1126/science.1072068

Olney, J. W., Rhee, V., and Ho, O. L. (1974). Kainic acid: a powerful neurotoxic analogue of glutamate. Brain Res. 77, 507-512. doi: 10.1016/0006-8993(74) 90640-4

Osawa, S., Iwasaki, M., Hosaka, R., Matsuzaka, Y., Tomita, H., Ishizuka, T., et al. (2013). Optogenetically induced seizure and the longitudinal hippocampal network dynamics. PLoS One 8:e60928. doi: 10.1371/journal.pone.0060928

Ozen, L. J., and Teskey, G. C. (2009). One hertz stimulation to the corpus callosum quenches seizure development and attenuates motor map expansion. Neuroscience 160, 567-575. doi: 10.1016/j.neuroscience.2009.02.066

Paz, J. T., Bryant, A. S., Peng, K., Fenno, L., Yizhar, O., Frankel, W. N., et al. (2011). A new mode of corticothalamic transmission revealed in the Gria4(-/-) model of absence epilepsy. Nat. Neurosci. 14, 1167-1173. doi: 10.1038/nn.2896

Paz, J. T., Davidson, T. J., Frechette, E. S., Delord, B., Parada, I., Peng, K., et al. (2013). Closed-loop optogenetic control of thalamus as a tool for interrupting seizures after cortical injury. Nat. Neurosci. 16, 64-70. doi: 10.1038/nn.3269

Pei, Y., Rogan, S. C., Yan, F., and Roth, B. L. (2008). Engineered GPCRs as tools to modulate signal transduction. Physiology 23, 313-321. doi: 10.1152/physiol. 00025.2008

Perucca, P., and Gilliam, F. G. (2012). Adverse effects of antiepileptic drugs. Lancet Neurol. 11, 792-802. doi: 10.1016/S1474-4422(12)70153-9

Pinel, J. P. J., and Rovner, L. I. (1978). Experimental epileptogenesis: kindlinginduced epilepsy in rats. Exp. Neurol. 58, 190-202. doi: 10.1016/0014-4886(78) 90133-4

Piomelli, D. (2003). The molecular logic of endocannabinoid signalling. Nat. Rev. Neurosci. 4, 873-884. doi: 10.1038/nrn1247

Pitkänen, A., Immonen, R. J., Grohn, O. H., and Kharatishvili, I. (2009). From traumatic brain injury to posttraumatic epilepsy: what animal models tell us about the process and treatment options. Epilepsia 50(Suppl. 2), 21-29. doi: 10.1111/j.1528-1167.2008.02007.x

Ponnazhagan, S., Mukherjee, P., Yoder, M. C., Wang, X. S., Zhou, S. Z., Kaplan, J., et al. (1997). Adeno-associated virus 2-mediated gene transfer in vivo: organtropism and expression of transduced sequences in mice. Gene 190, 203-210. doi: 10.1016/s0378-1119(96)00576-8
Racine, R. J. (1972). Modification of seizure activity by electrical stimulation: II. Motor seizure. Electroencephalogr. Clin. Neurophysiol. 32, 281-294. doi: 10. 1016/0013-4694(72)90177-0

Racine, R. J., Mosher, M., and Kairiss, E. W. (1988). The role of the pyriform cortex in the generation of interictal spikes in the kindled preparation. Brain Res. 454, 251-263. doi: 10.1016/0006-8993(88)90825-6

Rajasekaran, K., Todorovic, M., and Kapur, J. (2012). Calcium-permeable AMPA receptors are expressed in a rodent model of status epilepticus. Ann. Neurol. 72, 91-102. doi: 10.1002/ana.23570

Rakhade, S. N., Zhou, C., Aujla, P. K., Fishman, R., Sucher, N. J., and Jensen, F. E. (2008). Early alterations of AMPA receptors mediate synaptic potentiation induced by neonatal seizures. J. Neurosci. 28, 7979-7990. doi: 10.1523/ JNEUROSCI.1734-08.2008

Rancz, E. A., Franks, K. M., Schwarz, M. K., Pichler, B., Schaefer, A. T., and Margrie, T. W. (2011). Transfection via whole-cell recording in vivo: bridging single-cell physiology, genetics and connectomics. Nat. Neurosci. 14, 527-532. doi: $10.1038 / \mathrm{nn} .2765$

Rogawski, M. A. (2011). Revisiting AMPA receptors as an antiepileptic drug target. Epilepsy Curr. 11, 56-63. doi: 10.5698/1535-7511-11.2.56

Sajatovic, M., and Meltzer, H. Y. (1996). Clozapine-induced myoclonus and generalized seizures. Biol. Psychiatry 39, 367-370. doi: 10.1016/0006-3223(95) 00499-8

Salanova, V., Andermann, F., Rasmussen, T., Olivier, A., and Quesney, L. (1996). The running down phenomenon in temporal lobe epilepsy. Brain 119(Pt 3), 989-996. doi: 10.1093/brain/119.3.989

Sanchez-Blazquez, P., Rodriguez-Munoz, M., Vicente-Sanchez, A., and Garzon, J. (2013). Cannabinoid receptors couple to NMDA receptors to reduce the production of $\mathrm{NO}$ and the mobilization of zinc induced by glutamate. Antioxid. Redox. Signal. 19, 1766-1782. doi: 10.1089/ars.2012.5100

Sato, M., Racine, R. J., and Mcintyre, D. C. (1990). Kindling: basic mechanisms and clinical validity. Electroencephalogr. Clin. Neurophysiol. 76, 459-472. doi: 10.1016/0013-4694(90)90099-6

Sauer, B. (1987). Functional expression of the cre-lox site-specific recombination system in the yeast Saccharomyces cerevisiae. Mol. Cell. Biol. 7, 2087-2096. doi: 10.1128/mcb.7.6.2087

Sessolo, M., Marcon, I., Bovetti, S., Losi, G., Cammarota, M., Ratto, G. M., et al. (2015). Parvalbumin-positive inhibitory interneurons oppose propagation but favor generation of focal epileptiform activity. J. Neurosci. 35, 9544-9557. doi: 10.1523/JNEUROSCI.5117-14.2015

Shah, M. M., Anderson, A. E., Leung, V., Lin, X., and Johnston, D. (2004). Seizure-induced plasticity of h channels in entorhinal cortical layer III pyramidal neurons. Neuron 44, 495-508. doi: 10.1016/j.neuron.2004. 10.011

Shiri, Z., Manseau, F., Lévesque, M., Williams, S., and Avoli, M. (2015). Interneuron activity leads to initiation of low-voltage fast-onset seizures. Ann. Neurol. 77, 541-546. doi: 10.1002/ana.24342

Shorvon, S. D., and Goodridge, D. M. (2013). Longitudinal cohort studies of the prognosis of epilepsy: contribution of the national general practice study of epilepsy and other studies. Brain 136, 3497-3510. doi: 10.1093/brain/aw t223

Shu, X., Lev-Ram, V., Deerinck, T. J., Qi, Y., Ramko, E. B., Davidson, M. W., et al. (2011). A genetically encoded tag for correlated light and electron microscopy of intact cells, tissues, and organisms. PLoS Biol. 9:e1001041. doi: 10.1371/ journal.pbio.1001041

Silayeva, L., Deeb, T. Z., Hines, R. M., Kelley, M. R., Munoz, M. B., Lee, H. H. C., et al. (2015). KCC2 activity is critical in limiting the onset and severity of status epilepticus. Proc. Natl. Acad. Sci. U.S.A. 112, 3523-3528. doi: 10.1073/pnas. 1415126112

Sjöström, P. J., and Häusser, M. (2006). A cooperative switch determines the sign of synaptic plasticity in distal dendrites of neocortical pyramidal neurons. Neuron 51, 227-238. doi: 10.1016/j.neuron.2006.06.017

Sjöström, P. J., Rancz, E. A., Roth, A., and Häusser, M. (2008). Dendritic excitability and synaptic plasticity. Physiol. Rev. 88, 769-840. doi: 10.1152/physrev.00016. 2007

Sjöström, P. J., Turrigiano, G. G., and Nelson, S. B. (2003). Neocortical LTD via coincident activation of presynaptic NMDA and cannabinoid receptors. Neuron 39, 641-654. doi: 10.1016/s0896-6273(03)00476-8 
Sjulson, L., Cassataro, D., Dasgupta, S., and Miesenböck, G. (2016). Cell-specific targeting of genetically encoded tools for neuroscience. Annu. Rev. Genet. 50, 571-594. doi: 10.1146/annurev-genet-120215-035011

Soper, C., Wicker, E., Kulick, C. V., N'gouemo, P., and Forcelli, P. A. (2016). Optogenetic activation of superior colliculus neurons suppresses seizures originating in diverse brain networks. Neurobiol. Dis. 87, 102-115. doi: 10.1016/ j.nbd.2015.12.012

Sorokin, J. M., Davidson, T. J., Frechette, E., Abramian, A. M., Deisseroth, K., Huguenard, J. R., et al. (2017). Bidirectional control of generalized epilepsy networks via rapid real-time switching of firing mode. Neuron 93, 194-210. doi: 10.1016/j.neuron.2016.11.026

Staley, K. J. (2004). Role of the depolarizing GABA response in epilepsy. Adv. Exp. Med. Biol. 548, 104-109. doi: 10.1007/978-1-4757-6376-8_8

Storm, J. F. (1988). Temporal integration by a slowly inactivating K+ current in hippocampal neurons. Nature 336, 379-381. doi: 10.1038/3363 $79 \mathrm{a} 0$

Stripling, J. S., and Ellinwood, E. H. (1977). Augmentation of the behavioral and electrophysiologic response to cocaine by chronic administration in the rat. Exp. Neurol. 54, 546-564. doi: 10.1016/0014-4886(77)90256-4

Sukhotinsky, I., Chan, A. M., Ahmed, O. J., Rao, V. R., Gradinaru, V., Ramakrishnan, C., et al. (2013). Optogenetic delay of status epilepticus onset in an in vivo rodent epilepsy model. PLoS One 8:e62013. doi: 10.1371/journal. pone. 0062013

Sutula, T. P. (2004). Mechanisms of epilepsy progression: current theories and perspectives from neuroplasticity in adulthood and development. Epilepsy Res. 60, 161-171. doi: 10.1016/j.eplepsyres.2004.07.001

Teskey, G. C. (2001). "Using kindling to model the neuroplastic changes associated with learning and memory, neuropsychiatric disorders, and epilepsy," in Toward a Theory of Neuroplasticity, eds C. A. Shaw, and J. C. Mceachern (Philadelphia, PA: Psychology Press), 347-358.

Timofeev, I., Grenier, F., and Steriade, M. (2002). The role of chloride-dependent inhibition and the activity of fast-spiking neurons during cortical spike-wave electrographic seizures. Neuroscience 114, 1115-1132. doi: 10.1016/s03064522(02)00300-7

Tonnesen, J., Sorensen, A. T., Deisseroth, K., Lundberg, C., and Kokaia, M. (2009). Optogenetic control of epileptiform activity. Proc. Natl. Acad. Sci. U.S.A. 106, 12162-12167. doi: 10.1073/pnas.0901915106

Volgraf, M., Gorostiza, P., Numano, R., Kramer, R. H., Isacoff, E. Y., and Trauner, D. (2006). Allosteric control of an ionotropic glutamate receptor with an optical switch. Nat. Chem. Biol. 2, 47-52. doi: 10.1038/nchembio756

Wada, J. A., and Sato, M. (1974). Generalized convulsive seizure state induced by daily electrical-stimulation of amygdala in split-brain cats. Electroencephalogr. Clin. Neurophysiol. 37, 203-204.

Wagner, F. B., Truccolo, W., Wang, J., and Nurmikko, A. V. (2015). Spatiotemporal dynamics of optogenetically induced and spontaneous seizure transitions in primary generalized epilepsy. J. Neurophysiol. 113, 2321-2341. doi: 10.1152/jn.01040. 2014

Wang, Y., Xu, C., Xu, Z., Ji, C., Liang, J., Wang, Y., et al. (2017). Depolarized GABAergic signaling in subicular microcircuits mediates generalized seizure in temporal lobe epilepsy. Neuron 95, 92-105.e5. doi: 10.1016/j.neuron.2017. 06.004
Way, S. W., Rozas, N. S., Wu, H. C., Mckenna, J. III, Reith, R. M., Hashmi, S. S., et al. (2012). The differential effects of prenatal and/or postnatal rapamycin on neurodevelopmental defects and cognition in a neuroglial mouse model of tuberous sclerosis complex. Hum. Mol. Genet. 21, 3226-3236. doi: 10.1093/ $\mathrm{hmg} / \mathrm{dds} 156$

Weitz, A. J., Fang, Z., Lee, H. J., Fisher, R. S., Smith, W. C., Choy, M., et al. (2015). Optogenetic fMRI reveals distinct, frequency-dependent networks recruited by dorsal and intermediate hippocampus stimulations. Neuroimage 107, 229-241. doi: 10.1016/j.neuroimage.2014.10.039

Wicker, E., and Forcelli, P. A. (2016). Chemogenetic silencing of the midline and intralaminar thalamus blocks amygdala-kindled seizures. Exp. Neurol. 283, 404-412. doi: 10.1016/j.expneurol.2016.07.003

Wykes, R. C., Heeroma, J. H., Mantoan, L., Zheng, K., Macdonald, D. C., Deisseroth, K., et al. (2012). Optogenetic and potassium channel gene therapy in a rodent model of focal neocortical epilepsy. Sci. Transl. Med. 4:161ra152. doi: 10.1126/scitranslmed.3004190

Yekhlef, L., Breschi, G. L., Lagostena, L., Russo, G., and Taverna, S. (2015). Selective activation of parvalbumin- or somatostatin-expressing interneurons triggers epileptic seizurelike activity in mouse medial entorhinal cortex. J. Neurophysiol. 113, 1616-1630. doi: 10.1152/jn.00841.2014

Yizhar, O., Fenno, L. E., Davidson, T. J., Mogri, M., and Deisseroth, K. (2011). Optogenetics in neural systems. Neuron 71, 9-34. doi: 10.1016/j.neuron.2011. 06.004

Zemelman, B. V., Lee, G. A., Ng, M., and Miesenböck, G. (2002). Selective photostimulation of genetically chARGed neurons. Neuron 33, 15-22. doi: 10.1016/s0896-6273(01)00574-8

Zhang, F., Wang, L. P., Brauner, M., Liewald, J. F., Kay, K., Watzke, N., et al. (2007). Multimodal fast optical interrogation of neural circuitry. Nature 446, 633-639. doi: 10.1038/nature05744

Zhang, H. H., Zhao, H. T., Zeng, C., Van Dort, C., Faingold, C. L., Taylor, N. E., et al. (2018). Optogenetic activation of 5-HT neurons in the dorsal raphe suppresses seizure-induced respiratory arrest and produces anticonvulsant effect in the DBA/1 mouse SUDEP model. Neurobiol. Dis. 110, 47-58. doi: 10.1016/j.nbd. 2017.11.003

Zhang, Z., Russell, L. E., Packer, A. M., Gauld, O. M., and Hausser, M. (2018). Closed-loop all-optical interrogation of neural circuits in vivo. Nat. Methods 15, 1037-1040. doi: 10.1038/s41592-018-0183-z

Zingg, B., Chou, X. L., Zhang, Z. G., Mesik, L., Liang, F., Tao, H. W., et al. (2017). AAV-Mediated anterograde transsynaptic tagging: mapping corticocollicular input-defined neural pathways for defense behaviors. Neuron 93, 33-47. doi: 10.1016/j.neuron.2016.11.045

Conflict of Interest Statement: The authors declare that the research was conducted in the absence of any commercial or financial relationships that could be construed as a potential conflict of interest.

Copyright (c) 2019 Cela and Sjöström. This is an open-access article distributed under the terms of the Creative Commons Attribution License (CC BY). The use, distribution or reproduction in other forums is permitted, provided the original author(s) and the copyright owner(s) are credited and that the original publication in this journal is cited, in accordance with accepted academic practice. No use, distribution or reproduction is permitted which does not comply with these terms. 